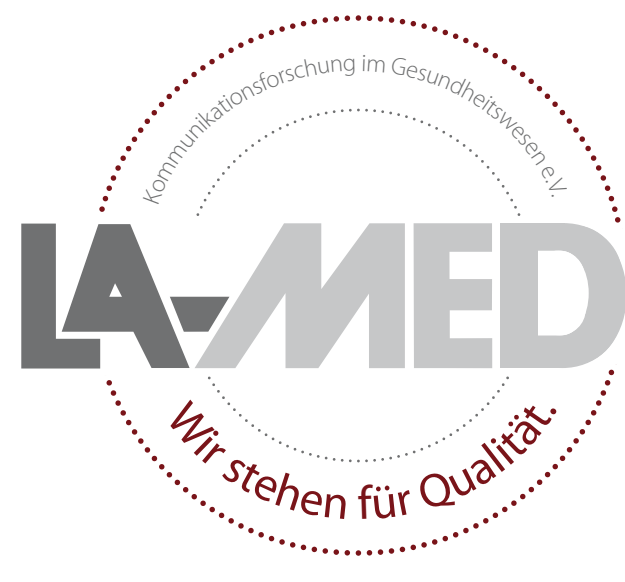

\section{Sie lesen Qualität}

Damit das auch so bleibt, befragen wir Sie in Kooperation mit tns infratest in den nächsten Wochen.

\section{Ihr Urteil ist uns wichtig.} Bitte nehmen Sie teil!

\title{
Der negative Test beruhigt nicht
}

\section{Es ist ein Trugschluss zu glauben, man könne ängstlichen Patienten mit negativen diagnostischen Tests ihre Angst vor einer schwerwiegenden Krankheit nehmen.}

- Mindestens die Hälfte der Patienten in der allgemeinärztlichen Praxis sucht den Arzt mit Symptomen auf, für die keine schwerwiegende Erkrankung als Erklärung dienen kann. Viele Ärzte ordnen selbst bei extrem geringer Wahrscheinlichkeit für ein positives Ergebnis zahlreiche diagnostische Tests an, in dem Glauben, sie könnten damit dem Patienten Ängste nehmen. Man kann auch immer wieder die Meinung hören, Patienten würden derartige Tests einfordern, wenngleich sie meistens gar nicht danach gefragt haben.

Während medikamentöse Therapieformen ein umfangreiches und strenges Zulassungsverfahren durchlaufen müssen, trifft dies bei diagnostischen Tests in deutlich geringerem Ausmaß zu, obwohl man damit bei unsachgemäßer Anwendung durchaus Schaden anrichten kann. In einer Suche in einschlägigen Datenbanken fand man 14 randomisierte und kontrollierte Studien mit zusammen 3828 Patienten, die die Frage untersuchten, ob die Ängste von Patienten kurz- bzw. langfristig durch diagnostische Tests beeinflusst werden können.

Drei Studien zeigten keinen Effekt diagnostischer Tests auf die Sorge, an einer schwerwiegenden Erkrankung zu leiden. Zwei Studien wiesen keinen Effekt auf unspezifische Ängste nach. In zehn Studien ergab sich kein langfristiger Effekt auf die Persistenz der Beschwerden und in elf Studien konnte zumindest eine Reduktion nachfolgender Praxisbesuche um durchschnittlich 33\% erzielt werden. Die Studien waren aber diesbezüglich sehr heterogen, da zur Vermeidung eines einzigen Praxisbesuchs zwischen 16 und 26 Patienten untersucht werden mussten.

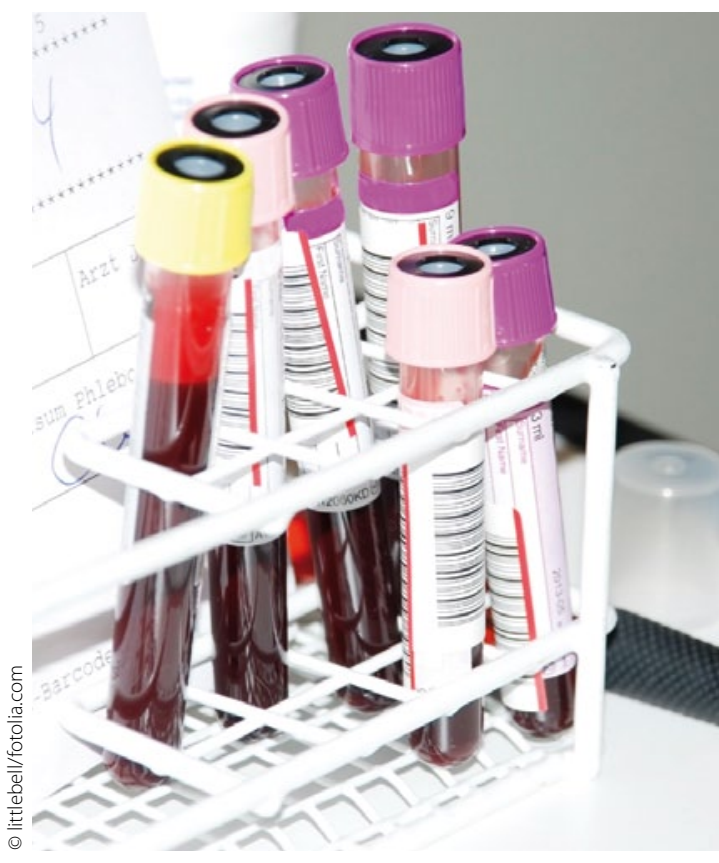

Bei ängstlichen Patienten bringt das Gespräch mehr als ein Test.

\section{Kommentar}

Die Untersuchung zeigt, dass es sich bei dem weit verbreiteten Glauben der Ärzte an die beruhigende Wirkung diagnostischer Tests auf beunruhigte Patienten um eine Fehleinschätzung handelt. Im Niedrigprävalenzbereich der allgemeinärztlichen Praxis ist die Wahrscheinlichkeit für eine schwerwiegende Erkrankung ohnehin sehr gering. Um den rein medizinischen Wert eines Screening von Alzheimer bis Zöliakie wird trefflich gestritten, und auch hier herrschen unter Ärzten oft völlig falsche Vorstellungen bezüglich der Effizienz. Als Beruhigungsmittel für ängstliche Patienten taugen diagnostische Tests nicht. Wenn überhaupt, so ist diesen Patienten noch am besten mit einem verständigen $\mathrm{Ge}$ spräch zu helfen.

H. S. FÜESSL ,

\section{- A. Rolfe und C. Burton}

(Korres.: c.burton@abdn.ac.uk): Reassurance after diagnostic testing with a low pretest probability of serious illness. JAMA Intern Med 2013; 173: 407-416. 